\title{
PREFACE TO THE ABRIDGED EDITION
}

7 his new edition of the Book of Lord Shang has two notable features. First, I abridged those sections that were too technical and could fit only a very few readers' interest. For instance, I have abridged the discussion that dealt with technicalities of ascertaining the dates of individual chapters. Readers who are interested in these details can consult my article in Early China that deals specifically with the dating of the Book of Lord Shang (Pines 2016a). I have also abridged many technical notes to the translation (e.g., "character X stands for character Y"), unless my choice had a major impact on the understanding of the text.

Second, this edition also underwent certain revisions and modifications. Most notably, I have improved the translation in several dozen places, in which colleagues had pointed at certain infelicities in the original translation. Moreover, I have slightly expanded the discussion of the text's reception during the Republican period (1912-1949), reflecting my new understanding of a few relevant points.

I hope that the resultant version will be both more easily accessible to the students and the general public.

Yuri Pines

December 2018 
